Annuaire suisse de politique de développement

26-2 | 2007

Financer le développement par la mobilisation des ressources locales

\title{
La coopération suisse au Mali : un positionnement original
}

Jean-Luc Virchaux

\section{(2) OpenEdition}

\section{Journals}

Édition électronique

URL : http://journals.openedition.org/aspd/152

DOI : $10.4000 /$ aspd. 152

ISSN : 1663-9669

Éditeur

Institut de hautes études internationales et du développement

Édition imprimée

Date de publication : 1 novembre 2007

Pagination : 225

ISBN : 978-2-88247-068-3

ISSN : $1660-5934$

Référence électronique

Jean-Luc Virchaux, «La coopération suisse au Mali : un positionnement original », Annuaire suisse de politique de développement [En ligne], 26-2 | 2007, mis en ligne le 22 juin 2009, consulté le 08 septembre 2020. URL : http://journals.openedition.org/aspd/152 ; DOI : https://doi.org/10.4000/aspd. 152 


\title{
La coopération suisse au Mali: un positionnement original
}

\author{
Jean-Luc Virchaux
}

a coopération suisse au Mali a concentré son travail sur l'enjeu des déséquilibres entre le centre et les périphéries. En choisissant de renforcer les capacités des collectivités territoriales de trois pôles de développement économique 1 , elle cherche à construire ses appuis progressivement, dans une démarche pédagogique d'appui budgétaire aux collectivités décentralisées en cohérence avec le processus de réforme de l'aide et en complémentarité avec la plupart des donateurs qui œuvrent sur la scène nationale. Ce positionnement original dans le paysage actuel des coopérations au développement, sachant que I'APD suisse se monte à 1,2\% environ de I'APD au Mali, apporte une perspective différente qui part du local pour remonter vers le national. Si le processus de réforme de l'aide qui privilégie l'appui budgétaire à l'Etat peut se prévaloir de résultats en termes de meilleure gestion de I'aide au niveau macroéconomique et d'un meilleur alignement sur les politiques et procédures du pays, il mériterait de mieux prendre en compte les principaux enjeux du développement aux niveaux méso- et microéconomique pour une efficacité concrète, quitte à altérer un tant soit peu l'orthodoxie de la réforme. La valeur ajoutée de l'appui de la coopération suisse au Mali paraît évidente, car celle-ci s'enracine non seulement dans une culture politique de construction des pouvoirs par le bas, ce que par tradition nous pouvons faire, mais aussi dans une expérience concrète de travail de terrain de plus de trente ans.

Le pôle des économies régionales à Sikasso, le pôle des économies cotonnières et vivrières à Koutiala et le pôle des économies lacustres à Youwarou, dans la région de Mopti. 